\section{The day before}

SIR - In a leading article in Nature of 1 December 1983 (p.412) it is recommended that ABC show the film "The Day After" again, and then again, in order that people do not forget the effects of an all-out attack with megaton weapons which have been extrapolated from the known effects of the 20 kiloton explosions over Hiroshima and Nagasaki.

I was struck by what seem to me to be significant omissions about what happened the day before: the actors portrayed in the film made almost no organized effort to improve their chances of survival. There are two scenes showing men shovelling small quantities of earth against the foundations of a church and a farmhouse, while there are innumerable scenes showing people panicking in city streets, grocery stores and on the highways. In one scene Dr Oats, the senior surgeon-haematologist, washes his hands at a scrub sink while an orderly tells him, in a tone of voice appropriate for the revelation that skinned cats have been found in the hospital kitchen, and that there is a rumour that people are leaving Kansas City. The question is asked, "Where does one go from Kansas City?",

It would have been even-handed and more interesting had the producers of the $\mathrm{ABC}$ film shown that the people of Kansas City could have moved into the large complex of commercially developed caverns which underlie the city and its environs. These caverns were art'ílciany excavated out of limestone to provide crushed rock for the Kansas and Missouri interstate highways. The excavated areas are covered by between 80 to 200 feet of bedrock and soil, have an even temperature $\left(57-62^{\circ} \mathrm{F}\right)$, a large area (several hundred acres) and are connected to each other and to the surface by many miles of roads and railroads. The Monsanto and Libby food companies have stored very large quantities of canned food and frozen fruit juice in the caverns, and other companies have stored cars, tractors and vodka. It has been estimated that everyone in Kansas City is within 45 minutes of one of the entrances to these caverns, and that the caverns could be used for blast and fallout protection' ${ }^{1}$.

Few cities have the opportunities for evacuation comparable with those of Kansas City, but then few cities are located beside 150 Minuteman missile silos. It has been estimated that an all-out attack with megaton weapons would kill or injure $50-80$ per cent of the unprotected population of the United States, and that the destruction of hospitals would make it impossible for physicians to "intervene effectively in the (resultant) human injury and death" 3 . These speculations have been repeated so often that many authors accept them as fact $^{3,4}$. However, these estimates assume that urban populations remain unprepared and unprotected. Most of the casualties from megaton weapons would result from the blast effects, and by removing people from the likely target areas, evacuation could substantially reduce the number of deaths ${ }^{5}$

In a broader context, it is critically important that the superpowers and their allies keep talking in order to reduce as much as possible the number of nuclear weapons and the likelihood that any of those weapons will ever be used. Until such talks have borne generous fruit, the nations of the Northern Hemisphere would be wise to emulate Sweden, Switzerland and the Soviet Union and improve their civil defence capabilities.

Royal Victoria Hospital,

ROBERT SHEPHERD

\section{Pine Ave West}

Montreal, Quebec, Canada

1. Halland, J. Civil Defense 12, 22-25 (1979).

2. Economic and Social Consequences of Nuclear Attacks on the United States, 46 (U.S. Government Printing Office. Washington, 1979; Stock no. 052-070-04889-1).

3. Cassel, C. \& Jameton, A. Annls internal Med. 97 $426-432(1982)$

Bates, D.G. Can. med. Ass. J. 125, pp $923-924$ (1981)

5. Defense Civil Preparedness Agency Attack Environment Manual, Ch.1 (U.S. Government Printing Office, Washington, 1973; Stock no. CPG 2-1A1).

\section{Crucifixion date}

SIR - I read with great interest the review article by Humphreys and Waddington entitled "Dating the Crucifixion" (Nature 306, 743-746; 1983). The date of 3 April, of the year AD 33, the 14 Nisan of the Jewish Calendar, appears to be well supported by their evidence. But one of their statements may be in error. They write ". . . we note ... that the Crucifixion must have occurred on 14 Nisan and that the interpretation of the Last Supper as a Passover meal held at the official time cannot be correct". However, it is likely that the official time for the Passover meal in AD 33 was on the night of 13 Nisan. In support of this view I present the following paragraph from $\mathrm{p}$. 326 of Jesus of Nazareth by Joseph Klausner (Macmillan, New York, 1944).

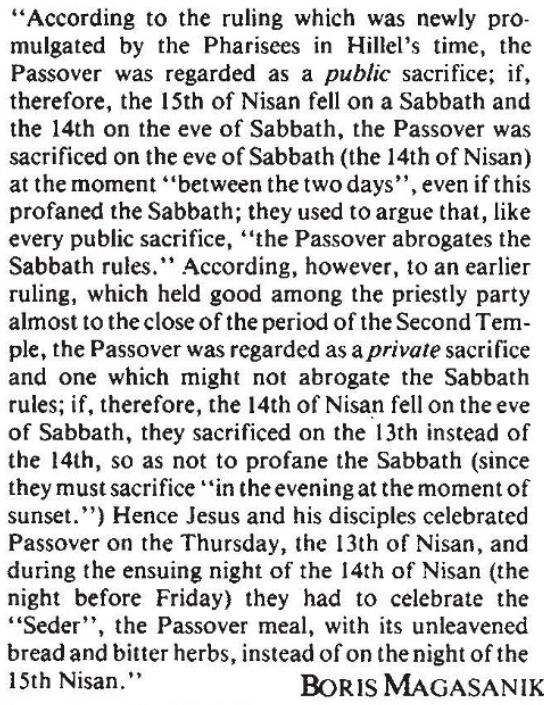

Department of Biology,

Massachusetts Institute of Technology, Cambridge, Massachusetts 02139, USA

\section{Animal rights}

SIR - Since you have established from recent correspondence that animal rightists are not only cranks but humourless ones to boot, it is without relish that I enter the fray. With one conclusion of your leading article (Nature 306, 527; 1983) I can entirely agree: there are no consistent or universal principles that imbue animals with "rights". A right, then, is not a given, an absolute, but is a function of the culture which accords it. Any right is a more or less widely accepted value built up over time and representing something of which we consider an animal or human should not be deprived.

While I can see no evidence for absolute natural rights of animals, to retain these for our own species while withholding them from other animal species is, in my view, antediluvian - or, to be more accurate, pre-Darwinian. What distinguishes this viewpoint from the ethnocentricity of those tribes whose members believe that they are the only humans and that people of neighbouring tribes can be killed like pigs?

Sir Andrew Huxley, president of the Royal Society, is reported to have asked what importance can be attached to the painless killing of purpose-bred laboratory animals that otherwise would not have lived. Man, according to this belief, has a right to destroy because he fancies that, like a god, he can create life. The surgeon Versalius used to say "I dressed him; God healed him." His antidote - a little humility.

STEWART BRITTEN

$9 d$ Stanhope Road,

London N6 $5 N E$, UK

\section{City slickers}

SIR - The proposal for an Indian "technology city" (Nature 305, 350; 1983) is welcome, but it is unfair to build such a city exclusively for Indian scientists working abroad. It is important to recruit the best of Indian scientific talent, no matter whether those concerned work in India or in the United States. While some of the best Indian scientists are working in India, not all Indian scientists working abroad are of high calibre.

I think the Government of India should go ahead with its plans but that it should appoint the best persons in the field, whether they are working in India or abroad. This could be achieved by a selection board comprising top ranking experts from India and other nations. There is always a risk that the very best scientists are not offered jobs in India for various sociopolitical reasons, but something has to be done if India is to keep pace with international developments.

Geology Department,

ARUN KUMAR

University of the West Indies,

Mona, Kingston 7,

Jamaica 